\title{
Factors influencing implementation of Quality Management Systems in meat processing industry in Albania using Ordinal Logistic Regression
}

${ }^{1}$ Dr. Ilir KAPAJ, ${ }^{1}$ Prof.Ass. Ana KAPAJ (MANE) (corresponding author), ${ }^{1}$ Dr. Eda DECI, ${ }^{1}$ Dr. Orkida TOTOJANI

${ }^{1}$ Agriculture University of Tirana, Faculty of Economy and Agribusiness, Tirana, Albania e-mail: amane@ubt.edu.al

\begin{abstract}
Objective of this research is to investigate how two attitudes of meat processing enterprises in Albania; 'Willingness to invest on ISO' and 'Perception about competition level' are affected by different factors belonging to internal and external environment of the organization.

Stratified random sampling was used for selecting the sample of 45 meat processing enterprises out of 54 officially registered. Face to face interview survey method was conducted. The respondents were mainly managers, owners or high level personnel of the selected meat enterprises. The model of ordinal logistic regression was used to quantify the effects of different management factors on 'Willingness to invest on ISO' and 'Perception about competition'. As result we conclude that the more information and knowledge enterprises have about ISO standards, the more they will have the willingness to invest on these standards. The next finding is that, if companies want to operate in national markets (high competition level) it is a good choice to do a benchmark analysis, also if enterprises in meat industry want to operate in high competitive markets the have to focus on after sales services and on product delivery.
\end{abstract}

Key words: Meat industry, Albania, QMS, Willingness to invest, Competition level

\section{Council for Innovative Research}

Peer Review Research Publishing System

Journal: International Journal of Management \& Information Technology

Vol.3, No.3

editor@cirworld.com

www.cirworld.com, member.cirworld.com 


\section{INTRODUCTION}

In the last decade quality has became of outmost importance to society. Consumers have become more conscious of quality, and organizations are now judged more on their overall quality performance instead of their financial performance alone. The most drastic change in quality thinking is probably the change from production-oriented to consumer-oriented concepts. Moreover, integrative approaches, system thinking, the focus on advanced technologies and belief in human capacities have had a considerable impact on current quality management (Schiefer 2002)

Quality has become a vital distinctive feature for competition in the world market food products. To obtain a good quality end product, quality is more and more managed along the whole food chain from the supplier of raw materials to the consumption. Striving for quality is not a free choice. Consumer understanding of food quality and the ultimate concern for health and food safety force actors in agribusiness and food industry to use quality management as a strategic issue in innovation and production (Luning, et al 2002).

Although before the nineties there existed a good tradition, the current industry of the meat processing is a relatively new industry in Albania, established mainly in these last 15 years. Exploiting all the possibilities and the resources and overcoming the difficulties faced during development, it has always managed to satisfy the quantitative needs of the Albanian consumers.

Nowadays the most important and delicate problem related to meat processing industry is the quality and safety of these products (avoiding elements in the content of these products that damage and endanger the health). This problem is becoming more sensitive as the meat industry is starting to prepare for introducing its products in a larger and more organized way in the foreign markets, but firstly in the European market.

In this study we are going to identify the factors that have an effect on implementing quality management standards by meat processing sector in Albania and also to quantify these effects.

Objective of this research is to investigate how two attitudes of meat processing enterprises in Albania; 'Willingness to invest on ISO' and 'Perception about competition level' are affected by different factors belonging to internal and external environment of the organization.

\section{MATERIALS AND METHODS}

Food industry in Albania has to achieve the quality standards in order to be competitive in future open markets (while aiming to enter in the EU countries). A large number of enterprises in food industry suffer for lack of information in the field of quality management and they need theoretical and practical training in this field (Kapaj, 2004). Based on the fact that agriculture and food industry sector is the largest contributor in the Albanian GDP, 23\% of GDP in 2008 (INSTAT, 2009), governmental policies in Albania aim further development of this sector.

Referring to a previous study (Kapaj, 2004) meat processing in Albania is dominated by small-scale companies, partly industrial producers (54 well-established private companies) and over 100 others operating as artisan ham \& sausage producers. The sector has noted increasing growth rates in terms of production, employment and investment, even one of the most growing sectors in the agro-food processing reaching $15 \%$ growth per year and with a current production value over Euro 55 million. Investments in the sector have increased in the recent years both on buildings and technology-wise. Market share of domestic sausages and ham is estimated to be over $90 \%$ with high import substitution norms in the recent years.

This research will consist in the identification and measurement of factors that influence 'Willingness to invest on ISO' and 'Perception about competition level' in meat processing industry in Albania. On the other hand managers based on this scientific research can orient their managerial efforts towards improving aspects of quality management. In this research most of our data are going to be ordinal data that have more than two categories. Multicategory logit models that deal with ordinal responses, assume that at each combination of the levels of explanatory variables, the response counts for the categories of $Y$ have a multinominal distribution. This generalization of the binomial applies when the number of response categories exceeds two (Agresti 1996:205). The core point of all multivariate techniques or models is to find if there is any association between dependent variables and independent variables, and if it is, measure the strength of the relationship. We will use the SPSS Ordinal Regression Procedure, or PLUM (Polytomous Universal Model), which is an extension of the general linear model to ordinal categorical data. We can specify five link functions as well as scaling parameters. The procedure can be used to fit heteroscedastic probit and logit models (Norušis 2008:69).

We will consider as dependent variable two categorical variables measured in Likert scale "Willingness to invest on ISO standards" and "Perception of companies about level of competition" (high, level of competition leading to an immediate need for quality improvement). As independent variables we will choose like "Level of knowledge about ISO standards", "Willingness to invest on training", "Operational markets", "Ration Export/annual turnover", "Level of compiling product technical specification", "Collaboration with R\&D department within organization", Benchmarking' etc. According to Agresti (1996) the measurement scale of independent variables in ordinal Logistic Regression can be of any type as it is in our case (nominal, interval, ordinal and ratio scale).

Meat processing in Albania is dominated by small-scale companies, partly industrial producers (54 well-established private companies) and over 100 others operating as artisan ham \& sausage producers. (MoAFCP, 2009). A stratified random sampling of 45 enterprises is selected for this study. Most questions in the questionnaire will be closed-ended. A code system will be developed to easy the data entry process. The data will be entered into Microsoft's Excel spreadsheet program and then imported into SPSS. The accuracy of data entry will be checked by frequency counts of each category. SPSS will be used to run Ordinal Logistic Regression model. 


\section{RESULTS}

We considered in the beginning the attitude of food and beverage enterprises in Albania towards investing in implementing widely recognized quality management systems and to be more specific we choose as dependent variables 'Willingness to invest in implementing ISO series' (1= Fully known, 2= Mostly known, $3=$ Medium known , $4=$ Poorly known, $5=$ Not known). By using the correlation matrix in SPSS we tried as many as 15 potential independent variables for finding any significant correlation, between dependent and independent variables. Although there were more than four variables that are correlated with dependent variable we couldn't found reliable regression model significance for all of them, but we found for four of them. So, as independent variables are considered the following variables

(a) Percentage of the export in relation to the annual turnover of the company $(1=$ Under $10 \%, 2=10 \%-30 \%, 3=31 \%$ $50 \%, 4$ = Over 50\%, 5 = No export)

(b) Operational markets of your organization (nominal variable coded $1=\ln$ the local markets, $2=$ In national markets, $3=$ International markets, $4=$ All markets)

(c) Company's willingness to invest for training regarding quality management $(1=$ Yes, $2=$ No, $3=$ Partially, $4=$ No answer)

(d) Level of knowledge about ISO 9001:2000 (1= Fully known, 2= Mostly known, 3 = Medium known , 4 = Poorly known, 5 = Not known).

Table 1: Relationships between 'Willingness to invest on ISO' and four different QM variables (own calculation and data). Willingness to invest on Export/ annual turnover Operational Willingness to invest Knowing ISO 9001 ISO

\begin{tabular}{lllll} 
ISO & $(\%)(\mathrm{a})$ & markets $(\mathrm{b})$ & for training $(\mathrm{c})$ & $(\mathrm{d})$ \\
\hline Correlation coefficient & $0.445^{\star *}$ & $-0.232^{*}$ & $0.229^{*}$ & $0.667^{* *}$ \\
Significance (2-tailed) & 0.000 & 0.029 & 0.039 & 0.000 \\
$\mathrm{~N}$ & 43 & 45 & 44 & 45 \\
& & & & 59.622 \\
-2 Log-Likelihood & 45.949 & 16.044 & 32.228 & 58.066 \\
Chi-Square & 16.931 & 6.114 & 7.003 & 4 \\
Degree of freedom & 3 & 2 & 2 & 0.000 \\
Significance & 0.001 & 0.047 & 0.030 & 0.504 \\
\hline Nagelkerke & 0.204 & 0.090 & 0.086 & -2.147 \\
\hline Parameter estimate & -1.840 & 0.936 & -0.396 & 8.526 \\
Wald statistics & 14.884 & 4.765 & 0.185 & 0.004 \\
Significance & 0.000 & 0.029 & 0.617 & 0.011 \\
\hline Exp (b) Odds ratio & 0.159 & 2.549 & NA & \\
\hline
\end{tabular}

a) Having a ratio of export/annual turnover les than $10 \%$ (1= less than $10 \%$ most of the enterprises not export at all) (Table 1) nis associated with likelihood of scoring 1 in the independent variable (Full willingness to invest on ISO standards $=1$ ) compare to scoring 2 (moderate willingness $=2$ ) by a factor of 0.159 . In other words, the lower ratio export/annual turnovers companies (scoring 1) the enterprises are more likely to have full willingness to invest for apply ISO quality management systems. Companies that have higher ratio export/annual turnover (scoring to the levels higher than 1), seems to lack willingness to invest. This behavior can be explained with the fact that since they export, they fulfill a certain quality management standards for export (perhaps ISO or other standards) and don't need to invest in ISO.

b) Independent variable 'Operational Markets: parameters estimate 0.936 . Operating in the local markets is associated with higher levels in dependent variable means, lack of willingness to invest on ISO (Table 1). Interesting is that as more enterprises expand the operational markets (going to the higher scoring levels), the chances that they will have the willingness to invest on ISO increase by a factor of 2.549 .

Conclusion: As food enterprises in Albania expand their operational markets it is more likely that they will have the willingness to invest in quality management standards. The logic behind this behavior make sense, if market become more competitive market, companies have to improve their quality to survive in that market.

Independent variables (c) and (d) have parameters estimate respectively -0.396 and -2.147 . Both are associated with lower scores in dependent, means higher willingness to invest on ISO. Although the parameter estimates for the variable (c) it is not significant $(p>0.05)$ we can still say that the companies that have the willingness to invest on training have also the willingness to invest on ISO.

For variable (d), it is interesting how strong is the effect size (Nagelkerke 0.504) between willingness to invest on ISO and level of knowledge about ISO standards. Nagelkerke coefficients vary from 0.086 to 0.504 representing weak to strong effect sizes.

Conclusion: As result we conclude that the more information and knowledge enterprises have about ISO standards, the more they will have the willingness to invest on these standards.

For dependent variable 'Competition level perception' ( $1=$ Very high, $2=$ High, $3=$ Low, $4=$ Absent) we applied again a correlation matrix and found five independent variables that are correlated significantly with dependent variable. Independent variables are:

(a) Is the benchmarking method used (comparison with the best) in your organization activities (coded $1=$ Yes, $2=$ No, 3 $=$ Not relevant).

(b)To what extent are you applying in your company client technical specifications ( $1=$ Fully, $2=$ Mostly, $3=$ Medium, $4=$ Poorly, 5 = Not at all).

(c) Is your company focused on delivery of product (coded $1=Y e s, 2=$ No, $3=$ No answer)

(d) Has your company compiled inter-operational specifications ( $1=$ Fully, $2=$ Mostly, $3=$ Medium, $4=$ Poorly, $5=$ Not at all). 
(e) To what extent is the collaboration between the person/marketing sector and the person/Research \& Development sector, Production, Quality control ( 1 = Very good, $2=$ Good, $3=$ Low, $4=$ Absent, $5=$ No collaboration).

Table 2: Relationships between 'Competition level (perception)' and five different QM variables from inside business environment (won calculation and data).

\begin{tabular}{|c|c|c|c|c|c|}
\hline Competition Level & $\begin{array}{l}\text { Benchmarking } \\
\text { (a) }\end{array}$ & $\begin{array}{l}\text { Applied client technical } \\
\text { specifications (b) }\end{array}$ & $\begin{array}{l}\text { Focus on } \\
\text { delivery (c) }\end{array}$ & $\begin{array}{l}\text { Compiling inter- } \\
\text { operational } \\
\text { specification(d) }\end{array}$ & $\begin{array}{l}\text { Collaboration of } \\
\text { R\&D with Prod. \& } \\
\text { QC (e) }\end{array}$ \\
\hline Correlation coefficient & $0.258^{\star \star}$ & $0.350^{* *}$ & $0.341^{* *}$ & $0.266^{\star *}$ & $0.345^{\star *}$ \\
\hline $\begin{array}{l}\text { Significance (2-tailed) } \\
N\end{array}$ & $\begin{array}{l}0.009 \\
45\end{array}$ & $\begin{array}{l}0.000 \\
44\end{array}$ & $\begin{array}{l}0.000 \\
45\end{array}$ & $\begin{array}{l}0.008 \\
45\end{array}$ & $\begin{array}{l}0.000 \\
43\end{array}$ \\
\hline -2 Log-Likelihood & 23.373 & 30.437 & 14.800 & 28.577 & 24.865 \\
\hline Chi-Square & 12.406 & 14.635 & 12.702 & 12.079 & 12.756 \\
\hline Degree of freedom & 3 & 4 & 1 & 4 & 3 \\
\hline Significance & 0.006 & 0.006 & 0.000 & 0.017 & 0.005 \\
\hline Nagelkerke & 0.135 & .0162 & 0.133 & 0.136 & .0142 \\
\hline Parameter estimate & -1.141 & -1.750 & 1.498 & -1.507 & -1.839 \\
\hline Wald statistics & 6.688 & 9.521 & 11.477 & 4.909 & 4.425 \\
\hline Significance & 0.010 & 0.002 & 0.001 & 0.027 & 0.035 \\
\hline Exp (b) Odds ratio & 0.320 & 0.173 & 4.472 & 0.221 & 0.160 \\
\hline
\end{tabular}

Independent variables (a), (b), (d), (e) have parameter estimates respectively $-1.141,-1.750,-1.507,-1.839$, (Table 2) which means that all variables are associated with a likelihood of lower values in dependent variables. In other words, if enterprises apply Benchmarking process in their activity they are more likely to have a perception that competition level in food market in Albania is high, also the same applies for the variable (b), if the enterprises apply client technical specification they are more likely to score in the lower levels of dependent (means their attitude towards competition is high), the same logic is for the variable (c). For the variable (e) a higher level of collaboration between R\&D sector and QC sector in company result in scoring lower in dependent variable, or means that the companies are more likely to have a high perception about the competition level in the sector.

The variable (c) has a parameter estimate 1.498 mean that is more likely to have a higher score in dependent variable (here low levels of perception regarding competition level in the market), Since this variable is a dichotomous variable don't focusing on product delivery $(0=\mathrm{No})$ is associated with lower levels of perception regarding the competition level (higher score levels). On the other hand going one level higher in independent variable (means focusing on product delivery 1 =Yes) increase the likelihood of scoring the next lower level in dependent (means higher attitude regarding competition by a factor of 4.472). Nagelkerke coefficients vary from 0.133 to 0.162 representing effect sizes less than moderate.

\section{CONCLUSIONS AND DISCUSSION}

According to the results from this study we came to the conclusion that enterprises have to invest on training with respect to quality and also have to invest in expertise and knowledge about ISO quality management systems. Also they have to expand their operational markets by food industry enterprises in Albania will results in higher attitude towards willingness to invest on ISO quality management systems.

If the companies want to operate in national markets (high competition level) it is a good choice to do a benchmark analysis and if the enterprises in the food industry want to operate in high competitive markets the have to focus on after sales services and on product delivery.

Also they must apply client technical specification, compile inter-operational specifications and have a good collaboration between sectors in their organization, in order to enter in high competitive markets.

\section{REFERENCES}

[1] Agresti, Alan. 2002. Categorical data analysis. Wiley series in probability and statistics. 2nd ed. New York: WileyInterscience.

[2] Dillman, D. A., (1978). Mail and Telephone Surveys. The Total Design Method. New York: Wiley.

[3] Hair, Joseph F. 2006. Multivariate data analysis. 6th ed. Upper Saddle River, N.J.: Pearson Prentice Hall.

[4] INSTAT, (Institute of Statistics), (2009). Statistical Yearbook 2004. Tirana, Albania.

[5] Kapaj, I. (2004). Assessing the quality and safety of the meat processing industry in Albania. Master theses. Stuttgart/ Germany

[6] Luning, L.A., Marcelis, W.J. and Jorgen, W.M.F., (2002). Food Quality Management: a Techno Managerial Approach. Wageningen Pers, Wageningen, Netherlands.

[7] Ministry of Agriculture Food and Consumer Protection. 2009, . Database for registered food and beverage enterprises in Albania. MoAFCP, Tirana.

[8] 2008. Database for registered food and beverage enterprises in Albania. MoAFCP, Tirana.

[9] Norušis, M. J. 2008. SPSS 16.0 advanced statistical procedures companion. Upper Saddle River, NJ: Prentice Hall.

[10] Schiefer, Gerhard. 2002. Quality management in agriculture and food : Management principles, system requirements, and development directions. 2. Aufl. ed. Vol. 94,2. Bonn: ILB. 